\title{
Digital Revolution and the Development of Tourism Business
}

\author{
Nikmah Suryandari ${ }^{1}$ \\ ${ }^{1}$ Communication Science, Faculty of Social and Cultural Science, \\ Universitas Trunojoyo Madura \\ Corresponding Author’s Email : nikmahsuryandari@gmail.com
}

\begin{abstract}
This paper tries to describe the impact of the digital revolution in the field of tourism. This paper aims to explain the effects of the digital revolution on the tourism sector. Tourism is one industry that is not affected by world economic conditions. On the contrary, tourism is actually growing rapidly with the support of technological advances and the digital revolution. This paper uses the document study method based on extracting data from a variety of important document sources that are relevant to the theme. Since the end of the twentieth century, the world has experienced a new scientific and technological revolution, which is rapidly influencing basic and applied research in various disciplines such as energy, and information and communication technology (ICT). ). the impact of this revolution on society and various fields of human activity is increasingly apparent. In the case of travel and tourism the impact of ICTs and the Internet in general is very significant, bringing with it a new digital economy, new actors, their new "rules of play", the new business models they need, and an increasing level of interaction with all of us. Over the next few years we will see how much technology trends have developed and have far more intensive impacts along the entire value chain of the tourism sector.
\end{abstract}

Keywords: effects, digital revolution, tourism

\section{INTRODUCTION}

The effects of the revolution on society and various human activities are increasingly visible. In the context of tourism and travel business, the impact of internet-based information and communication technology has changed very significantly. This change creates a new digital economic model, new actors, their new "rules of the game", a business model, and an increased level of interaction with everyone (interconnection). Digital economy is based on a completely new infrastructure with new capabilities (telecommunications networks, hardware and software), new ways of doing e-business and e-commerce development(Mesenbourg 2001).

At the end of the 20th century, the world underwent a new technological revolution that quickly influenced a variety of basic and applied research in various sciences, such as quantum physics, biomolecular chemistry, energy, and information and communication technology. In the end, the progress of various 
sciences and technologies has a significant impact on the field of travel and tourism business.

\section{Manuel Castells: Informationalism, Network Society, and Capitalism}

Manuel Castells is a leading figure in the development of information society theory. Castells is a scientist who studies the development of information technology. In view of advances in information technology has provided a "material basis" for "pervasive expansion" of what is known as a form of social networking of organizations in every state of social structure. Pervasive is a situation where technology has been integrated with the users of the technology and the environment so that the technology is not a special thing. In other words, technology has become a part of his life. For example the use of a smartphone by someone to support their daily activities. When the smartphone is left behind, it impacts the feeling of uncertainty. Manuel Castells has many views on the development of the information society. Among them is regarding the concept of Informationalism in network society and capitalism. In general, there are six things that illustrate the information society according to the perspective of Manuel Castells, namely informationalism, network society, global economy or informational economy, workforce transformation, global city and cyberculture.

In the era of contemporary or post-industrial modern society, in contrast to industrial society or capitalism which gave birth to the working class or workers who spend their daily time in factories, in the era of post-industrial society, the development of information technology and the power of information has given birth to new lifestyles, symbols and "white-collar workers" who are more engaged in services, especially jobs and businesses that are more involved in the process of managing information and using it for economic and social, even political, interests. In the 1990s, the United States and other developed countries have begun to launch modern information infrastructure development programs or what are called information superhighways that are actually based on this vision (Kuper \& Kuper, 2000).

The information superhighway is a new telecommunications infrastructure based on the development of fragmented technologies, such as telephones, facsimiles, computer communication cables, and satellites, which has created high-speed traffic and triggered the emergence of cyberspace. High-speed information, namely the convergence of various technologies into integrated information technology and the growth of important values of knowledgeintensive services financially, has created a new technical and economic basis for the capacity of the transporter (Abercrombie et al., 2010: 279)

In the post-industrial era, almost no aspect of human life can be separated from the presence of information technology. The presence of television, cellphones, computers, and the internet is a variety of information technology devices that quickly change people's life patterns and styles. The idea of this information society was actually first offered by Daniel Bell in the early 1970s 
through his prediction when it came to the post-industrial society. This discussion of the information society was further developed by Manuel Castells through the concept of a network society.

Castell further developed the concept of Daniel Bell, and expressed his four views on the emergence of a new society, culture and economy from the point of view of the information technology revolution, such as television, computers and so on (Rizter \& Goodman, 2008). The emergence of informational capitalism and information society is based on "informanism", where the main source of productivity lies in optimizing the combination of the use of knowledge and information-based production factors. Castell believes that information plays an important role in the organization of economic activity in the exporting society. The application of knowledge (knowledge) and information produces a process of technical innovation that is accumulative in nature and has a significant effect on social organizations (Castell, 2000: 16-17,32).

Castell explained the development of society in the late 19th century which was influenced by the development of information and information technology as a network society (netwok society). In the era of post-industrial society, the existence of networks enables the flow of communication to go anywhere and at any level of the structure without the need to be mediated or represented. Castell states that what really develops is not just an information society, but an informational society.

In an informational society, Castell states there are two important elements that are adequate, namely: 1 . There is a global expansion of business operations through the construction of complex transnasocial relationships. 2. Consolidation of economic networks with information networks (Castells, 2007: 77-78). Castells (2000: 28-76) develops ideas about the informational community by referring to the five basic characteristics of information technology, namely: 1. Information is a raw material for economics 2. Information technology has broad effects on society and individuals 3 . Information technology provides the ability to process information which allows network logic to be applied to economic organizations and processes. 54 . Information technology and network logic allow for much greater flexibility, with the consequence that processes, organizations, and institutions can easily be altered and new bar forms are constantly created 5 . Individual technology has been reduced to an integrated system.

In the era of post-industrial society, one important thing is what Castell calls "network". The existence of this "network" has enabled capitalism to be globalized and organized based on global financial experience. The development of transitional companies that work in various countries, could never have happened if it had not been supported by information technology that was able to integrate networks and communications in an integrated manner. Castell sees that accompanying the rise of this global informational economy, which is called a network enterprise (network enterprise), that is a specific form of company whose facility system is built from the intersection of a number of autonomous destination system segments. This network company is an embodiment of a global 
informational economic culture that enables the transformation of signs into commodities. In addition to network companies there is also the emergence of virtual real culture, which is a system in which reality itself is fully encompassed and fully enters into virtual image settings, in a fantasy world, in which the appearance is not only in the place where experience is communicated, but also in cyberspace.

In Castells' view, the emergence of networked society stems from the historical convergence of three independent processes, is

1. The technological revolution, which was formed as a 1920s paradigm

2. Restructuring capitalism and statism in the $1980 \mathrm{~s}$

3. Socio-cultural movements of the 1960s, and then the 1970s, in particular feminism and ecology.

\section{LITERATURE REVIEW}

\section{Digital Power and Change in the Tourism Industry}

Rapid technological developments have completely changed the tourism industry through digital media. In recent years, digital media has contributed in promoting destinations or attractions.

The media has a crucial role in the growth and progress of tourism, one of which is by conveying in-depth information about tourist objects needed by domestic and foreign tourists. In the era of technological advances, there is a change in the behavior of tourists where they want more information about attractions. Tourists or consumers are more active looking for information on social media before they take a vacation somewhere. After they take a vacation, tourists often share their experiences of hotels, restaurants, airlines and attractions.

Based on Digital 2020 revealed that internet users around the world have reached 4.5 billion people. This figure shows that internet users have reached more than 60 percent of the world's population or more than half of the earth's population.

Technological developments and the digital revolution have a direct impact on the tourism sector. this is due to the following:

1. Emergence of the internet 


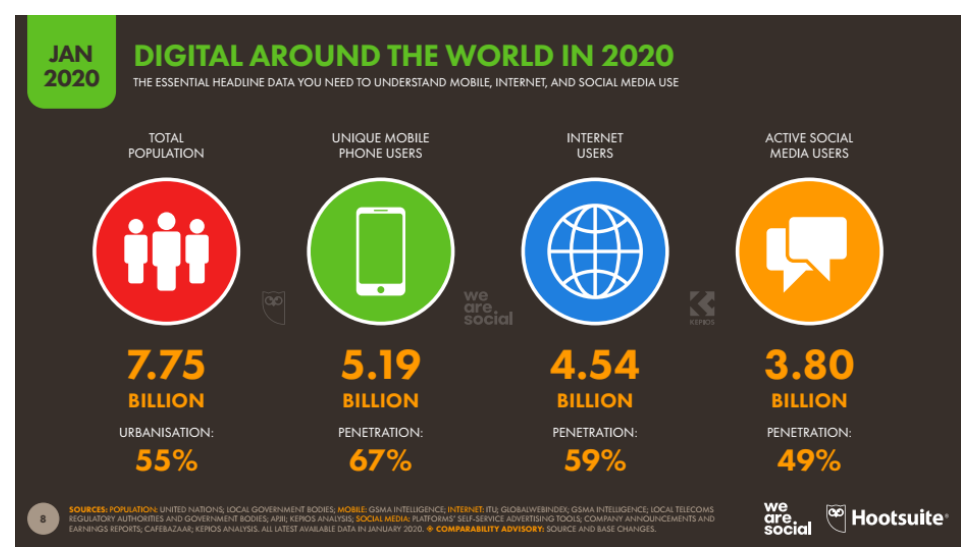

Source : We are Social x Hootsuite

\section{Internet penetration in several parts of the world}

The idea of the internet being a basic human need seems to be seen in several countries of the world. Based on the ranking, from more than 200 countries in the world there are five countries in the world whose internet penetration number has reached 99 percent. That means almost every citizen can enjoy internet access.

These countries are Iceland, Kuwait, Qatar, United Arab Emirates and Bahrain. The five countries are countries with income per capita above 50,000 dollars per year. For the coming years, of course more and more countries will be able to achieve internet penetration of close to 100 percent. Given there are still hundreds of millions of users in various parts of the world that have not been accessed by the internet and most of the population that has not been accessed is in Asia, whose economies continue to grow, such as India and China.

\section{Internet use behavior}

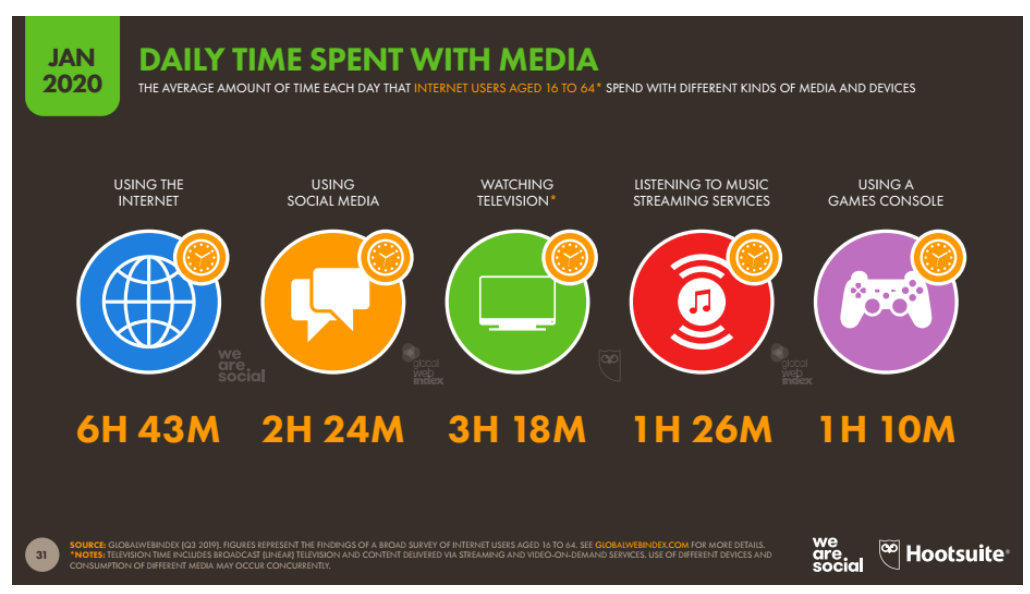

Source : We are Social x Hootsuite 
According to this Digital 2020 report, internet usage from a matter of hours tends to decrease. Because when compared with 2018 the use of the internet in 2019 decreased for three minutes. From 6 hours 46 minutes to 6 hours 43 minutes in 2019.

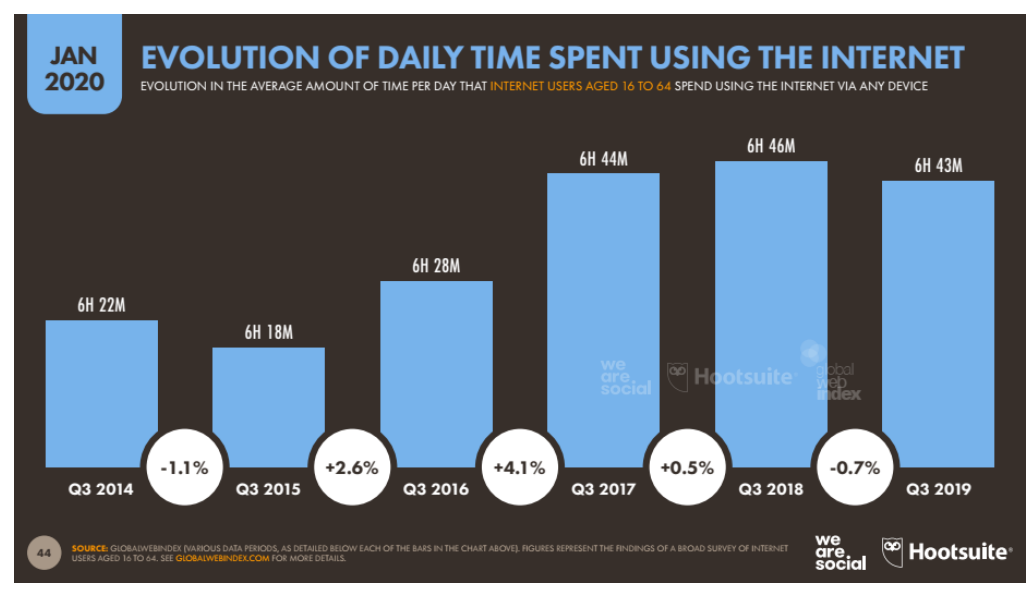

Source : We are Social x Hootsuite

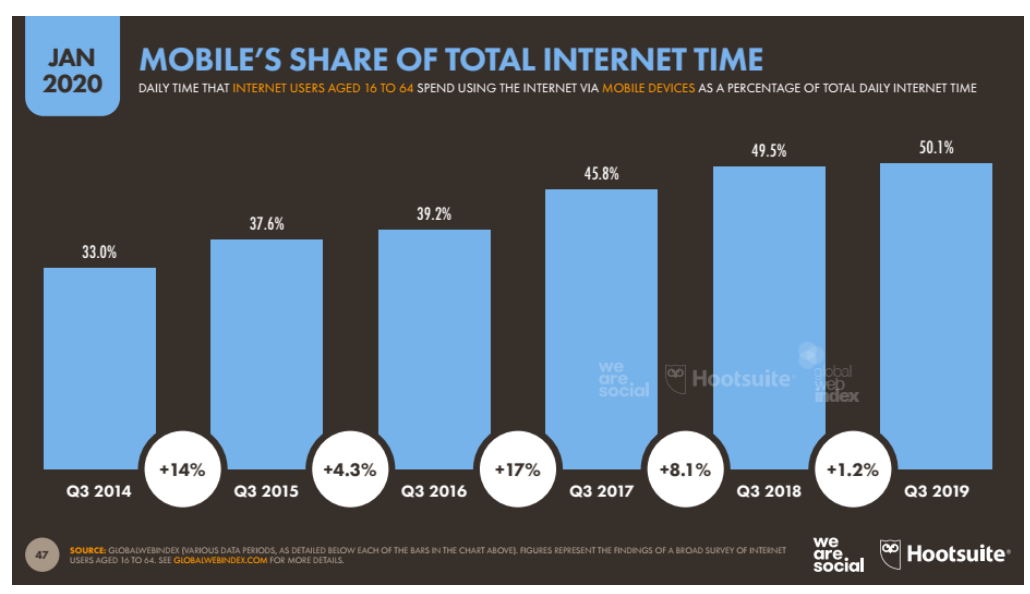

Source : We are Social x Hootsuite

Apart from the long decline in internet usage, internet usage through mobile devices tends to increase. An increase of $0.6 \%$ from 2018 to 2019 so that the total use of the internet via mobile devices is $50.1 \%$ of the total internet usage, equivalent to 3 hours 35 minutes. The duration of using the internet through a mobile device for 3 hours 35 minutes is of course quite a long time for a daily activity 
2. Increase in the number of smartphones

This statistical data states the number of smartphone users around the world from 2014 to 2020. In 2016, the number of smartphone users is estimated to reach 2.1 billion. While the number of cellphone users worldwide is expected to exceed five billion by 2019 . The number of smartphone users is expected to continue to grow from 2.1 billion in 2016 to around 2.5 billion in 2019, with the penetration rate of this smart device which also increased. More than 36 percent of the world's population is projected to use smart phones in 2018, this figure is up about 10 percent in 2011. China, which is the most populous country in the world, is a country that also leads the smart phone industry.

The number of smartphone users in China is expected to grow from around 563 million in 2016 to nearly 675 million in 2019. About half of the Chinese population is projected to use smart phones by 2020. The United States is also an important market for the smart phone industry, with around 223 million smartphone users in 2017. By 2019, the number of smartphone users in the US is expected to increase to 247.5 million.

Google Android and Apple iOS are the two most popular smartphone operating systems in the industry. In 2016 alone, nearly 1.5 billion smartphones with the Android or iOS operating system were sold to end users worldwide. Android leads the market with 80 percent of smartphone sales. In contrast, around 15 percent of all smartphones sold to end consumers have iOS as their operating system. Leading smartphone vendors are Samsung and Apple, with around 20 to 25 percent and 15 percent of their respective shares, followed by Huawei, OPPO and vivo.(Statista,2018)

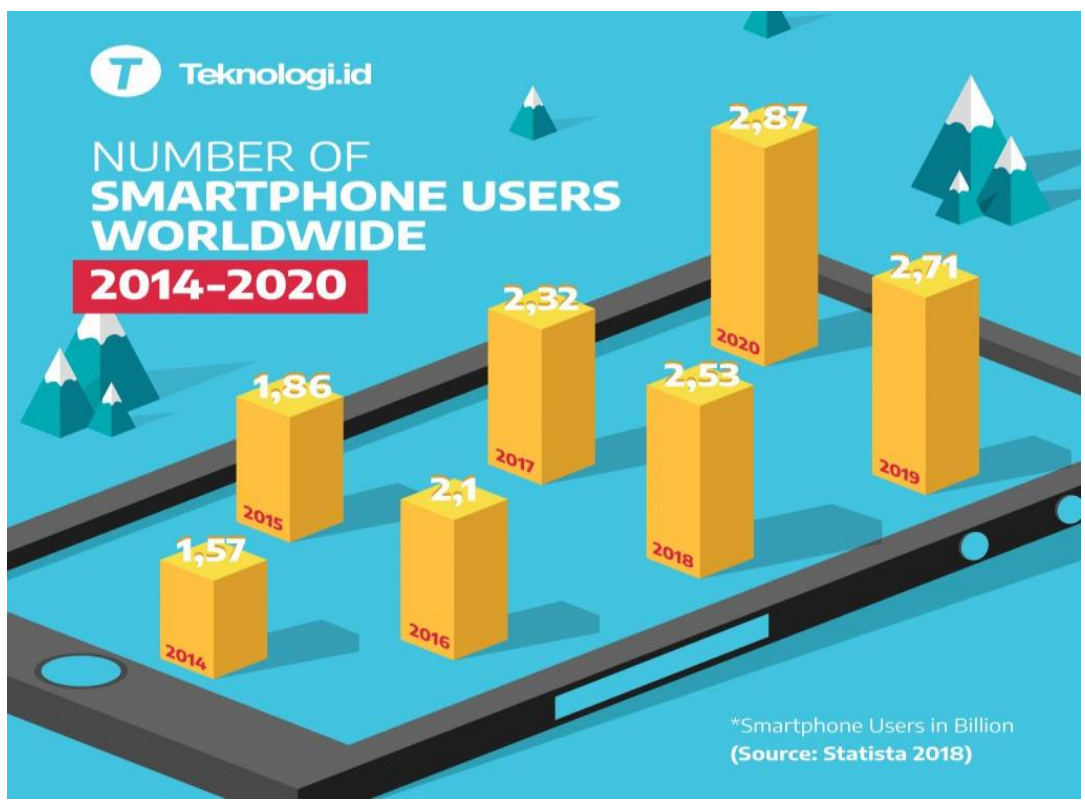

3. Emergence The Internet of Things 
The Internet of Things (IoT) is becoming an increasingly hot topic of discussion in the era of the industrial revolution 4.0 because the concept has not only the potential to affect our lifestyle but also how we work.

Internet of Things (IoT) is a computing concept about everyday objects that are connected to the internet and are able to identify themselves to other devices. According to the RFID (Radio Frequency Identification) identification method, the term IoT belongs to the communication method, although IoT can also include other sensor technology, wireless technology or QR codes (Quick Response). Internet connection is an amazing thing, it can give us all kinds of benefits that might have been difficult to obtain before. We can see the sophistication of this IoT by comparing old phones with smartphones.

We can call and send text messages with your old cell phone. But, now you can read books, watch movies, or listen to music through a smartphone connected to the Internet. So, the Internet of Things is a fairly simple concept, which means connecting all physical objects in everyday life to the Internet. The term "Internet of Things" consists of two main parts namely the Internet that regulates connectivity and Things, which means objects or devices.

Simply put, we have "Things" that have the ability to collect data and send it to the Internet. This data can be accessed by other "Things" as well. Three main benefits that you will get directly from IoT:

\section{Connectivity}

In this digital age, we can say goodbye to the era of operating devices manually. With IoT, we can operate many things from one device, such as a smartphone.

\section{Efficiency}

With an increase in connectivity, there is a decrease in the amount of time normally spent doing the same task. For example, voice assistants such as Apple's Homepod or Amazon's Alexa can provide answers to questions without you needing to pick up the phone or turn on the computer.

\section{Ease}

IoT devices such as smartphones are now starting to become the devices most people have.

The Internet and mobile devices are playing a key role in the disruptions impacting tourism in the early twenty-first Century, but a potentially more dramatic change looms on the horizon: the Internet of Things, also known as IoT.

IoT refers to embedding Internet-ready sensors inside everyday physical objects like buildings, appliances and vehicles. IoT is already shaping up as a transformative force in different sectors and activities. Increasing numbers and types of objects can now connect to Internet, and the volume of data they generate is growing. In the near future, there will be more objects online than people. Being connected to the Internet means these items can be identified, they can receive and send information, as well as receive instructions from other equipment, just like human users. In other words, these are objects with a certain 
level of intelligence, as is already happening with our televisions, fridges, thermostats and trainers.

This new world is much "smarter" (Smart TVs, Smart watches, Smart cities and destinations), and more interconnected. Everything is becoming connected to everything else, with the physical dimension coexisting with the digital and social dimensions, creating hybrid, multichannel worlds and experiences that are now practically inseparable.

Some forecasts consider that 8.4 billion connected things will be in use worldwide in 2017 , up $31 \%$ from 2016, and will reach 20.4 billion by 2020 and the total spending on endpoints and services will reach almost \$2 trillion in 2017 (Gartner 2017). Although it is true that we are still at the beginning of this trend to ubiquitous connectivity, the boom in smartphones, which we are using for more tasks every day, plus the growth in smart city and destination projects, increasingly connected infrastructure, practically omnipresent wireless connections, and ever more pervasive Internet access, will certainly be accelerating in the next few years.

As the real world becomes more digitised, the convergence between the physical and the virtual worlds becomes increasingly transparent for companies, users, destinations, and in general for anyone with this information. New companies and business models emerge based on new types of services leveraging the advantages of this new environment and the new rules of the game.

The opportunities created by IoT are still moving forward in many sectors, including tourism, and some airlines, airports, hotels and destinations have already implemented pilot initiatives to bring their customer's both online and offline experiences, and we will certainly see more of this in the years to come.

\section{Big Data : The Biggest Valuable Resource}

So far there is no definitive definition of what big data is, but many experts are trying to provide a definition of big data. According to Wikipedia Big Data is a phrase used to mean a massive volume of both structured and unstructured data that is so large that it is difficult to process using traditional database and software techniques. In most enterprise scenarios the volume of data is too big or it moves too fast or it exceeds current processing capacity. Meanwhile according to Edd Dumbill Big data is data that exceeds the processing capacity of conventional database systems. The data is too big, moves too fast, or doesn't fit the strictures of your database architectures. To gain value from this data, you must choose an alternative way to process it.

From the two definitions above we might conclude that Big Data is data that has a large volume so that it cannot be processed using traditional traditional tools and must use new methods and tools to obtain values from this data. Every day we create a lot of data, this data can come from anywhere; post to social 
media sites, digital images and videos, purchase transaction records and others. This data is big data.

Big data technology appears to solve a problem or facilitate the resolution of a problem. There are 3 main problems that big data try to solve, namely with $3 \mathrm{~V}$; Volume, Velocity, Variety.

One of the problems big data is trying to solve is the explosion in the volume of data that an organization wants to store or process. How much data can be processed at this time? The data currently available is very large. In 2000 alone there were 800,000 petabytes of data stored worldwide and this figure is expected to reach 35 zettabytes in 2020 or even more. Is this data volume problem can only be solved by big data?

how fast we are able to get the results of an analysis of the flow of data that continues to flow at almost the same time that the data arrives. The data rate created is generally directly proportional to the data volume. Data not only comes in large numbers, but also in a shorter tempo and even some are real-time.

Variety is a problem that occurs because of the diversity of data, both from the incoming data file format, and the format / structure of the data contents. Big Data does not only consist of structured data such as numeric data or rows of letters originating from a basic database system as well as a financial database system, but also consists of multimedia data such as text data, voice data and video known as data unstructured. Big Data also includes half-structured data as well as e-mail and XML data.

\section{Cloud Replaces Internal Storage}

An Android smartphone with support for an external memory slot is considered a 32-64GB size as a minimum limit now, and this number will continue to grow. This is because our digital data storage needs are increasingly large. From applications, documents, photos, music, videos and so on. For quite some time the cloud (storage) feature was introduced, from free to paid, where we can store our data on a data server somewhere in the world from cloud storage providers such as Google, Microsoft, Apple, and other third parties.

The existence of this cloud makes it easy to access and backup our data from many devices. Only unfortunately, the access speed is not as fast as when we access data directly from our device storage.

The presence of $5 \mathrm{G}$ with data speeds many times faster than $4 \mathrm{G}$ LTE, enables data access in this cloud as fast as we access data in internal storage. Thus, a smartphone or laptop with greater internal storage, will feel no longer needed. We will rely on our data in the 'cloud'. We will need a large cloud storage, compared to internal storage of a large smartphone or laptop, and the transfer or replacement of devices is no longer a hassle with having to move data from old devices to new devices. 
The existence of cloud computing in the digital era has actually been felt in the midst of society in everyday life such as the use of email and also social media.

In general, the definition of cloud computing (cloud computing) is a combination of the use of computer technology (computing) in a network with internet-based development (cloud) which has the function to run programs or applications through computers - connected at the same time, but not all connected through the internet using cloud computing.

This cloud system based computer technology is a technology that makes the internet a central server for managing data and also user applications. This technology allows users to run programs without installation and allows users to access their personal data through computers with internet access.

6. The Smart Wearables

Smart Wearable devices can be interpreted as a combination of the latest technology and equipment or accessories that we usually use, such as watches, glasses, cameras, bracelets, and so on. Most of the wearable device technology is influenced by the development of smart phone technology, so some of them still need smart phones to be able to operate optimally such as Apple Watch, Razer Nabu, and Google Glass.

\section{Faster Connectivity and More Capacity}

When we use smartphones, laptops, PCs, and many other digital equipment, when not connected to the internet, the functionality of the equipment will be very limited.

Before the era of wireless broadband, there were quite a lot of activities we could do with the equipment. But now, when the internet connection has become the backbone, we feel that many ways and our activities with these various tools have changed.

We see the presence of social media changing our habits of contact, digital news presence has blown away many print media, video streaming is starting to replace the need for television networks, online sales affect many traditional stores, and more.

The presence of digital technology will change our habits and bring new characteristics to the speed of Multi-gigabit

With this speed, if we download a HD movie that was just finished in minutes or hours, it will be finished in seconds.

Besides high speed, digital technology has a large capacity to make it unlimited data

8. The Spreading of Social Networks 
In the last five years the number of internet users in the world has experienced significant growth. We Are Social and Hootsuite data records that the earth's population that has been connected to the internet in 2018 reached four billion compared to the 2014 position of only 2.4 billion people. This figure shows the level of internet penetration has reached $52.96 \%$ of the total world population which reached 7.59 billion inhabitants. In 2014, global internet penetration only reached $35 \%$ of the total population.

The average growth of internet usage annually reaches an average of $11 \%$, with the highest growth recorded at $21.2 \%$ to 3 billion people in 2015 from the previous year of 2.4 billion people.

The increase in communication and information technology as the network coverage expands and the cheap price of devices becomes the driving force for the increase in mobile users and global social media. Mobile device users in 2018 experienced a growth of $67.63 \%$ to 5.14 billion compared to 2015's new position of 3.65 billion. Likewise, social media users in the year reached 3.2 billion accounts, which means it grew $42.1 \%$ from the 2014 position of 1.86 billion accounts. (https://databoks.katadata.co.id/datapublish/2018/07/23/4-miliarpenduduk-bumi-telah-terkoneksi-internet)

By ranking Facebook is still the most popular social media in the world with 2.449 billion accounts. Again an astounding number because half of the world's social media usage is for Facebook. While the rest is shared with other social media. The second rank is occupied by Youtube with 2 billion accounts. In third place is Instagram with 1 billion accounts. Next up is an astonishing newcomer namely Tiktok with 800 million accounts.

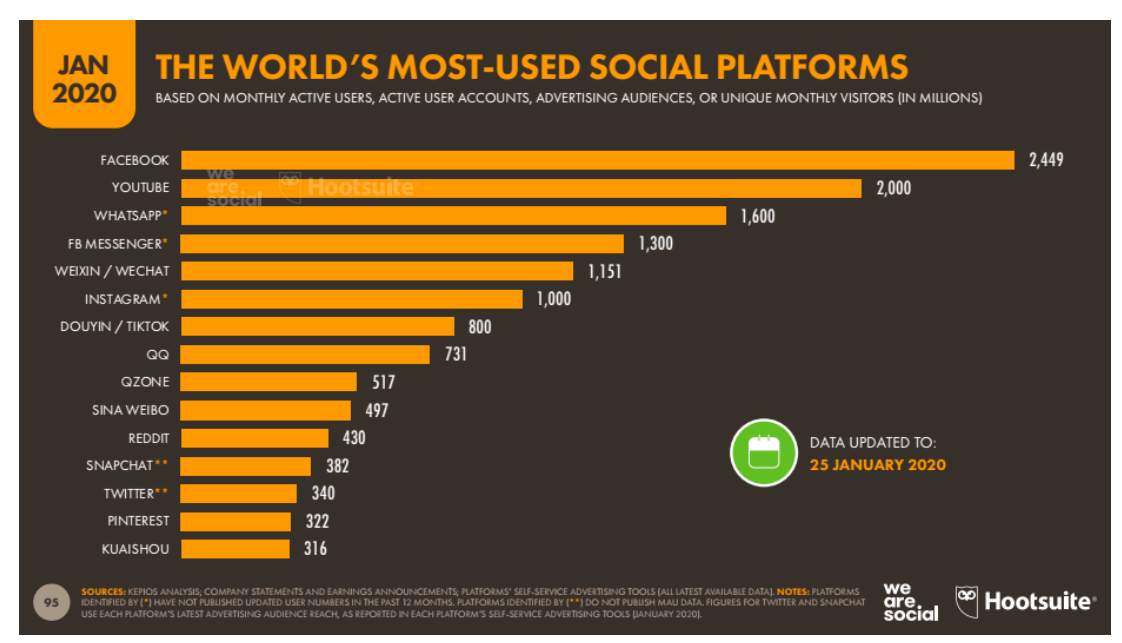




\section{Artificial Intelligence}

Artificial Intelligence is one of the technologies that are currently popular. Various fields of industry have utilized the technology, ranging from health, finance, and others.

Not only that, Artificial Intelligence has also been widely applied in everyday life. Artificial Intelligence helps many people to communicate, find locations, shop and much more.

Artificial Intelligence or artificial intelligence is a computer system that is capable of performing tasks that normally require human intelligence. This technology can make decisions by analyzing and using data available in the system. The processes that occur in Artificial Intelligence include learning, reasoning, and self-correction. This process is similar to humans doing analysis before giving a decision.

\section{METHODOLOGY}

The documentary method is one type a method often used in social research methodologies, relating to collection techniques the data. This method is widely used in scope historical studies. But now document studies are widely used in other social science fields research methodology. Most of the facts and lots of social data are stored in documentary material. Therefore the current social sciences seriously make studies documents in the data collection technique.

According to Sugiyono (2005: 83 ) document study is a complement to the use of observation methods and interviews in qualitative research. Even the credibility of the results of qualitative research will be increasingly high if it involves / uses document studies in the qualitative research method.

\section{RESULTS AND DISCUSSION}

\section{Digital Revolution and Travellers Behavior}

The development of technology that connects information throughout the world, also makes traveling easier. It is proven that technology can influence and shape the way a person performs tourist activities, starting from planning a trip, while on a trip, until returning from his trip.

The stages of using technology in making a tour include:

1. Planning: Online Reservations

Nowadays when someone travels, flight ticket reservations and majority lodging use online reservation. The presence of supporting online reservation applications makes it easy to order so that it is in high demand by people in this digital age.

2. On the way (On The Road): Mobile Phone is The best Co-pilot 
The presence of a smartphone to be the best guide in a tour. When someone travels he can get various information only with his smartphone. Starting from the tourist places that you want to visit, how to get to those places, where to eat typical of an area, to where souvenir shopping can be known with the smartphone that we have.

3. After the Trip (Post-Trip): Sharing is Living

The rise of social media is currently changing people's lifestyles, currently sharing or posting our activities into the daily habits of the people of Indonesia, is no exception when we are on a tour.

The emergence of the 4.0 revolution era in the digital era is marked by easy access or information through digital media. The digital age is the cause of the emergence of phenomena in the tourism sector. Klaus schwab's approach to revolution 4.0 was first presented in his writing The Fourth Industrial revolution which explains the birth of the industrial revolution marked by the integration of technology as the cause of biased boundaries between fields, physical, digital and biological.

Changes and developments in this revolutionary era lead to the same key, namely through the use of the power of digitalization of information, conservation of technology that occurs through the use of digitalization of information, termed as the Internet of things (IoT).

This term is defined as the relationship between various types of things such as products, services, places and so on with people. This relationship occurs through the use of information accessed through various forms of platforms (Schwab 2016).

This era is one of the causes of many shifts in the social situation of people in various important sectors of the world including the tourism sector as one of them. In the IOT era tourism sector has an impact on the emergence of digital transformation which is the cause of the birth of digital tourism 4.0.

This digital transformation is changing the whole cycle of the tourism ecosystem, which includes the cause of the shifting of cyber and visual culture to tourists. The shift in cyber culture seen from digital transformation in the digital era of tourism 4.0 is the process of changing the call of decision in conducting tourism activities and travel.

Cyber culture that focuses on social phenomena and networking makes social media have a significant role as a source of reference for tourists in determining the tourist destination that will be visited .

Around $85 \%$ of world tourists explain uploading video photos and social media platforms that affect their travel plans. A similar statement was conveyed by getler hans, where social media has become one of the global megatrends in the development of tourism in the digital age which significantly impacts the tourism ecosystem and influences the decision making process for traveling

In the digital era of tourism 4.0 the dissemination and consumption of information on social media related to tourism activities becomes important to 
the development of tourism. So that tourists who come to visit tourist destinations that are none other than to capture the moment "selfii" where later the term taking a selfii has become an important part of traveling

So that the concept of digital tourism emerges for the development of an area or tourist destination with a selfie spot destination approach. The impact of the emergence of tourism in the digital era 4.0 include:

(1) Shifting the cyber culture in the tourism sector related to the use of social media as marketing tools through the role of the community.

(2) A shift in visual culture towards tourists that has an impact on the birth of digital destinations in Indonesia.

It cannot be denied that the rapid development of the internet is an important indicator in seeing the development of tourism in the digital age 4.0. Indonesia is a country with the largest internet users in the world with a growth rate of around $51 \%$ which refers to the use of social media such as Facebook, Instagram, bloggers and the like with income from the digital economic sector through transactions in the range of around Rp74.6 trillion (We are in Asia 2017) .

\section{Digital Tourism 4,0: Shitf in Tourism Sector}

The term digital tourism has indeed begun to develop rapidly in several countries including Indonesia. Where digital tourism means the use of digital (internet) in the tourism industry which includes management and marketing. Digital tourism can also be concluded utilizing internet facilities with various media that are close to the community such as social networking

Facebook, Instagram, Tumblr, Twitter, Blog, Micro Blog, Website and Email). The development of tourism in the digital era 4.0 has various advantages. Among these are:

(1) Cost effective as well as its main needs is the availability of internet connection when compared with conventional tourism development.

(2) Accurate mapping so that target markets can be determined easily both in terms of demographics and interests so that market mapping is more accurate.

Besides having the advantages of digital tourism also has several shortcomings in its development including:

(1) Digital tourism must require internet access which may not yet be available in all tourist areas.

(2) Human resources who understand applied digital technology and are able to manage Management Information System (MIS), and Customer service System (CSS).

The digital age of Pariwisata 4.0 has made significant changes to the tourism ecosystem, especially in millennial generation. Where since the shift of millennial cyber culture has massively taken advantage of the digital platform to access a number of information related to tourism. 
The 4.0 era digital tourism approach is responding to changing tourist habits that lead to hyperconected society patterns through the policy of developing digital tourism areas that are packaged through "current" digital marketing strategies.

Where for further development of digital tourism need to consider several important aspects, namely:

(1) Positioning specifically developed to respond to changes in millennial economic esteem trends.

(2) Differentiating, that is the form and process of marketing communication to be a differentiator in the development of digital tourism where the concept of development must be developed with the concept of "instagramable" Where in its application the photo spots must be widely spread around the tourist area so that all of these spots can be visually pleasing and feasible posted by travelers on his social media account.

(3) Branding is an approach to tourism development through the "Destination approach now" with the concept conveyed to tourists as a "Unique Selling Proposition" (USP) in which the success of digital viral tourism is promoted.

Departing from this approach, the development of tourism in the digital era 4.0 is changing communication patterns from pre-existing areas to marketing communications so that development can be achieved in accordance with the needs and target markets.

Other important elements in seeing the development of digital tourism in the 4.0 era can be seen through several important stages, namely:

(1) Through the identification of each uniqness human resources possessed by each tourism area by starting to initiate community involvement and GENPI which has an important role as hyper local travel enthusiasts, hyper local destination experts and hyper local attraction specialists.

(2) The next step that must be taken is to promote the tourism area into the online realm by entering and involving the community that has been formed through a mainstream social media platform that is used by millennials (3) building a digital tourism business cycle by proposing sponsorship of related parties so that it can gradually expand the realm of promotions being carried out.

The development of digital tourism can be formed and sustainable (sustainable) only if there is collaboration in the active involvement of all stakeholders in the tourism sector in Indonesia. Stakeholders or termed with the Five stakeholders (Penthahelix) involved such as:
(A) Academics,
(B) Business Sector,
(C) Community, 
(D) Government,

(E) Media must complement each other and have the same building vision

In the Industrial Revolution 4.0, Klaus Schwab, Founder and Executive Chairman of the World Economic Forum in his book The Fourth Industrial Revolution, argued that the fourth generation industrial revolution was marked by the emergence of super computers, smart robots, vehicles without drivers, genetic editing and the development of neurotechnology that enable humans to further optimize the ability of brain function.

The existence of the Industrial Revolution 4.0 resulted in changes in consumer behavior that became increasingly digital, especially Gen $Y$ (millennial generation) and Gen $\mathrm{Z}$ (screenage generation) the greater the number and influence so that the term always-connected travelers emerged, wherever and whenever they were connected with each other mobile apps / devices.

The existence of this industrial revolution is changing the lifestyle of tourists in finding information for trips, which previously they planned a vacation always rely on travel agents or travel agents, but now they are comparing products, ordering tour packages, and various latest information that can be done digitally by telephone cellular, in short they search and share using digital media.

The keywords for this digital lifestyle are mobile, personal, and interactive, this is done by tourists in looking around and looking for information (look), then order a tour package that they are interested in (book), continued payment online, if the platform still uses media conventional like television or newspapers, the process cannot be digitally integrated with a booking company (book) or an online payment company (pay).

The use of big data in a digital platform is able to get more precise consumer behavior insights, and is easily accessible to tourists from anywhere in the world, so the tagline The more digital, the more personal. The more digital, the more professional. The more digital, the more global.

Millennials are now very happy to self-actualize by downloading various activities such as where, with whom, what activities and all of that is more toward the individual so that a destination must be able to create experiences, memorable and testimonials.

For marketing activities there is a very fundamental change, where customers were initially considered as objects, now there is a shift to the subject so that conventional marketing will have difficulty finding customers, new toolboxes such as online booking system, messenger and WhattsApp, Google analytics, Facebook, Instagram , Tweeter, to make it easier to access, analyze, communicate and various other needs.

In principle, marketing is more towards the communication process from sender to receiver, but in the process there is always noise that will interfere in the delivery of responses or feedback, for that we need to find creative steps to eliminate noise, one way is to utilize a story, this is because visuals are processed faster in the brain than data and numbers, the frequency 
waves of the story makers will be the same as those who hear or see them and most importantly $90 \%$ of the information transmitted to the brain is visual.

Industry players must change to follow the desires of consumers, both business models, how to market, or other strategies, from traditional to digital so that they are not left behind and can survive.

In the end, tourism businesses are able to manage the business ecosystem supported by artificial intelligence, Big Data, Super Apps, Broadband Networks, Internet of Things and Cloud computing, bringing new values and proven results are extraordinary.

\section{Cyberspace Culture Shift}

The digital age will have a significant impact and change in world trade in the future. The digital economy has doubled compared to 2008 which only reached 2 percent of world GDP. Growth for the next five years is estimated at 11 percent per year.

Digital commerce is part of the digital revolution that will bring a very broad impact for the entire region.

From the information he received, as many as 1.8 billion inhabitants in Asia Pacific Economic Cooperation (APEC) countries had transacted online at the end of 2015. The number is equivalent to 65 percent of APEC's population of 2.85 billion people.

Online services that have a market of USD 1.6 trillion are expected to grow 13 percent per year until 2020. As much as two-thirds of the value comes from eretail and e-travel.

Over time, the industrial revolution continued to develop. Now, the world tourism industry has faced the next revolution, the fourth industrial revolution or the digital revolution. This era is characterized by the emergence of various and changes that occur in technology that have an impact on various fields, one of which is the marketing aspect. Marketing has now shifted from the concept of traditional marketing to digital marketing, where trading has reached seconds because all transactions are done online. The digital revolution has also changed the behavior of tourists towards marketing. Changes in tourist behavior can be seen from the way they search, pay, use up to do a review of goods and services purchased.

Tourism 4.0 aimed at millennial tourists is characterized by changes in behavior that tends to be more independent and individual. Chinese millennial tourists, formerly known as "group tourism", are now becoming more individual tourism. Millennial tourists groups currently dominate the countries of world tourists.

Tourism 4.0 in several of its main destinations by building digital ecosystems ranging from inspiration, arrival, destinations, to all-digital post-trips reflecting the era of tourism 4.0 
Changes in market behavior are followed by changes in customer behavior that is increasingly mobile, personal, and interactive and this is the nature of digital, which is increasingly digital, more personal (the more digital, the more personal).

In the tourism industry, changes in consumer behavior can be seen when the search and share of $70 \%$ has gone through digital. The travel agent industry can no longer rely on walk-in service for ticket reservations and choosing tour packages. Everything has changed with the digital system.

The emergence of the 4.0 industrial revolution, he continued, had an impact on the emergence of the tourism 4.0 era in the tourism sector. This era is marked by the ease of access to information through digital media.

The era of tourism 4.0 is also the cause of the emergence of the phenomenon of shifting cyber and visual culture in Indonesian tourists, especially the generation of mile $\neg$. Responding to this, all developments and changes of this revolution, led to the same key, namely through the use of the power of digitalization of information.

Departing from the power of digitalization, technological convergence that occurs through the use of digitalization of information, is termed the period of the internet of things (IoT).

The IoT era has become one of the causes of many shifts in the social situation of the people in various important sectors of the world. One of the tourism sector. In the tourism sector, the IoT era has an impact on the emergence of digital transformation which is the cause of the birth of tourism 4.0 trends.

Digital transformation changes the whole cycle of tourism ecosystems, including the cause of the shifting of cyber and visual culture to tourists. This era has made significant changes to the tourism ecosystem, especially in millennial generation. Where, since the shift of cyberspace culture, millennials have massively exploited digital platforms to access a number of information related to tourism.

Apparently, this has a connection to the changing interests of millennial tourists about a destination from the visual side. Now, millennials are more interested in visiting tourist destinations because they want to capture their selfie moments. This has finally become a cycle, in which the shift of cyberspace culture is related to how visually millennial is moved to travel.

Entering the era of the industrial revolution 4.0 will fundamentally change the face of various industries, including the tourism industry. The industrial era 4.0 will fundamentally change and disseminate the tourism industry with the realization of cost value, known as more for less, experience value personalization, and value sharing platform platform that travelers enjoy.

\section{CONCLUSION}

There are several technological trends currently occurring in the world and have a significant impact in the entire tourism sector : 
- The use of Big Data and artificial intelligence can enhance tourist experiences and custom types of services. This service is about the ability to personalize services to tourists based on their profile, their context, habits and general consumer behavior. Implementation of this service will significantly modify the marketing process, support the product personalization process and improve tourism services.

- The era of the digital revolution has succeeded in integrating the physical world with the digital world. This technology can generate experience for guests before or during their trip, as well as offering a preview of what they can enjoy at their destination, increasing tourist satisfaction

- The power of search engines and processing in the tourism business. The potential is extraordinary, with service oriented to speed and response.

- Prioritize the emotional needs of tourists through big data services and the adequately implemented Internet of Things.

\section{BIODATA}

Nikmah Suryandari is a lecturer of Communication Science Dept on Universitas Trunojoyo Madura, Bangkalan, Indonesia. She has a research interest in intercultural communication, health communication and media studies.

\section{REFERENCES}

Castells, M. (1996). The rise of the network society. Oxford: Blackwell. Accessed November 15, 2016, from https://deterritorialinvestigations.files.wordpress.com/2015/03/manuel _castells_the_rise_of_the_network_societybookfi-org.pdf

https://databoks.katadata.co.id/datapublish/2018/07/23/4-miliar-penduduk-bumitelah-terkoneksi-internet

Davenport, T. H. (2013). At the big data crossroads: Turning towards a smarter travel experience. Madrid: Amadeus IT Group.

Domingo, P. (2015). The master algorithm: How the quest for the ultimate learning machine will remake our world. London: Penguin.

European Commission. (2015). 5G vision: The 5G infrastructure public private partnership: The next generation of communication networks and services. European Commission. Accessed April 22, 2017, from https://5g-ppp.eu/wp-content/.../02/5G-Vision-Brochure-v1.pdf

European Commission. (2016). Smart wearables: Reflection and orientation paper. European Commission. Accessed April 22, 2017, from https://ec.europa.eu/newsroom/document.cfm? doc_id $=40542$

Future Foundation. (2016). Millennial traveller report: Why millennials will shape the next 20 years of travel, expedia. Accessed October 2, 2016, 
from https://blog.expedia.co.uk/wp-content/ uploads/2016/10/ExpediaMillennial-Traveller-Report.pdf

Gartner, Inc. (2017). Gartner newsroom. Accessed April 22, 2017, from https://www.gartner.com/ newsroom/id/3598917

Internet Live Stats. (2017). Accessed June 2, 2017, from http://www.Internetlivestats.com/

SEGITTUR. (2015). Smart destinations report: Building thefuture. Accessed February 15,2017, from http://www.segittur.es/opencms/export/sites/segitur/.content/galerias/des cargas/documentos/ Libro-Destinos-Inteligentes-en-Ingls.pdf

Sugiyono ( 2005 ). Memahami Penelitian Kualitaif. Alfa Beta. Bandung

ThinkwithGoogle. (2014). Travel content takes off on YouTube. Accessed June 1, 2017,from https://www.thinkwithgoogle.com/consumerinsights/travel-content-takes-off-on-youtube/

Tourism Economics an Oxford Economics Company. (2013). Impact of online content on European tourism. Accessed February 15, 2017, from http://sete.gr/_fileuploads/entries/Online\%20library/GR/131204_The\%2 0Impact\%20of\%20Online\%20Content $\% 20$ on\%20

European\%20Tourism.pdf

Travel Report. (2017). Accessed June 1, 2017, from http://travelreportmx.com/wp-content/uploads/ $\quad 20 \quad 12 / 1$ 1/ecosistemaviajesonline1 .png.

We are Social x Hootsuite

We are in Asia ( 2017)

Zhang, Q., Lu, C., \& Boutaba, R. (2010). Cloud computing: State-of-the-art and research challenges. Accessed April 22, 2017, from http://citeseerx.ist.psu.edu/viewdoc/download?doi=10. $\quad 1.1 .471$ $.7902 \&$ rep $=$ rep $1 \&$ type $=$ pdf 